04

\title{
Зависимости теплофизических параметров активированных термоэмиссионных катодов от тока в стационарном дуговом разряде
}

\author{
() Б.Д. Цыдыпов, И.Г. Симаков, С.Б. Базарова
}

Институт фризического материаловедения СО РАН, Улан-Удэ, Россия

I E-mail: baz_say@mail.ru

Поступило в Редакцию 18 апреля 2018 г.

Исследовано влияние силы тока (в диапазоне 20-150 А) на теплофизические характеристики активированных термокатодов $\left(\mathrm{W}+2 \% \mathrm{ThO}_{2}\right)$ в свободногорящей аргоновой дуге пониженного давления. Впервые получены зависимости основных параметров катодов: теплового потока в электрод, вольтова эквивалента тепла, удельной эрозии, распределений температуры и работы выхода электронов по длине вылета из катододержателя. Отмечена немонотонная зависимость удельной эрозии от силы тока с минимальным уровнем при $50-60 \mathrm{~A}$.

DOI: $10.21883 /$ PJTF.2018.19.46680.17336

В сильноточных плазменных установках различного назначения широко применяются термоэмиссионные катоды из тугоплавких металлов [1-4]. В качестве материала катодов чаще всего используется вольфрам, активированный компонентами из окислов редкоземельных элементов с низкой работой выхода электронов еф [3]. Уровень эрозии и соответственно ресурс работы термокатода зависят от его теплофизического состояния и динамики выхода легирующего элемента (присадки) из объема основного металла. Поэтому исследование этих характеристик в зависимости от заданных параметров плазменной системы весьма актуально [4,5]. Для оптимизации токовых нагрузок в дуговых разрядах атмосферного давления основное внимание авторов, как правило, уделяется экспериментальному исследованию тепловых потоков в электрод $Q_{h}(I)$, удельной эрозии $G(I)$, температуры $T(r, z)$ и плотности тока $j(r, z)$ активной зоны катодов в зависимости от силы 
тока $I$ [4-7]. В настоящей работе измерены профили температурного поля $T(z)$ и работы выхода электронов $е \varphi(z)$ по длине вылета из катододержателя в стационарном дуговом разряде пониженного давления, комплексно изучаются зависимости основных теплофизических параметров от тока.

Схема экспериментальной установки аналогична представленной в [8]. В вакуум-герметичной камере объемом 2001 в среде $\mathrm{Ar}$ между стержневыми электродами с полусферическими рабочими торцами зажигается дуговой разряд длиной $30 \mathrm{~mm}$. Катод из торированного вольфрама ВТ-15 (диаметр $d_{c}=4 \mathrm{~mm}$, длина вылета $L_{c}=10 \mathrm{~mm}$ ) устанавливается в катододержатель цанговой конструкции. Анод из поликристаллического вольфрама $\left(d_{a}=10 \mathrm{~mm}, L_{a}=25 \mathrm{~mm}\right)$ запрессован в корпус интенсивно охлаждаемой медной обоймы. Зависимости теплофизических параметров от тока измерены в диапазоне 20-150 А при фиксированном давлении аргона $p=1.33 \cdot 10^{4}$ Ра. При этом давлении реализуется чисто испарительный механизм эрозии и отсутствует унос материала в виде капель и отдельных сколов, наблюдаемых на вольфрамовых катодах в дуге атмосферного давления, т.е. обеспечивается минимальный уровень удельной эрозии катода [9].

Для измерения параметров на токовых нагрузках 20, 30, 50, 75, 100, 125 и 150 А из цельного прутка вольфрама ВТ-15 изготавливался набор одинаковых электродов длиной $20 \mathrm{~mm}$ и диаметром $4 \mathrm{~mm}$. При этом для каждого значения тока использовался новый катод. Методом контактной разности потенциалов на установке, аналогичной [10], определялся исходный профиль $е \varphi(z)$ по длине катода. Зажигался дуговой разряд и после $60 \mathrm{~min}$ непрерывной работы катода измерялись профиль температуры $T(z)$, размер опорного пятна дуги и тепловой поток в электрод. После этого ток отключался, катод снимался с держателя, определялись распределение $е \varphi(z)$ и эрозия электрода. Методы измерения, применяемые в эксперименте, и их погрешности описаны в [8,9]. Особенностью исследования является проведение измерений характеристик катодов в дуговом разряде пониженного давления в условиях слабого охлаждения электродного узла. Такой подход позволяет при атмосферном давлении в достаточно узком диапазоне рабочих токов (20-150 A) получать тепловые режимы, характерные для интенсивно охлаждаемых узлов сильноточных плазмотронов $\left(10^{2}-10^{3} \mathrm{~A}\right)$.

На рис. 1 представлены токовые зависимости теплового потока в катод $Q_{h}(I)$, вольтова эквивалента тепла $V_{h}(I)$ и удельной эрозии $G(I)$

3 Письма в ЖТФ, 2018, том 44, вып. 19 


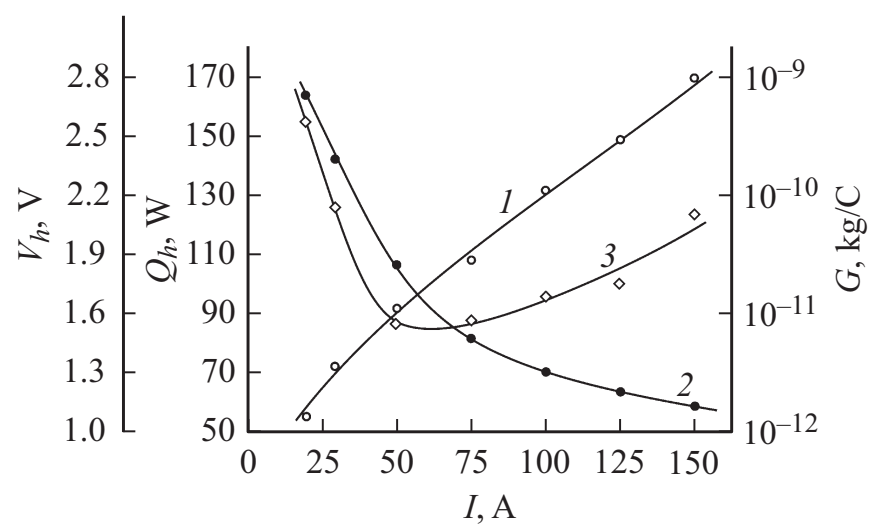

Рис. 1. Зависимости теплового потока в катод $Q_{h}(I)(1)$, вольтова эквивалента тепла $V_{h}(I)$ (2) и удельной эрозии $G(I)$ (3) от тока $I$ после $1 \mathrm{~h}$ работы $\left(p=1.33 \cdot 10^{4} \mathrm{~Pa}\right)$.

после $1 \mathrm{~h}$ работы термокатода. Видно, что зависимость $Q_{h}(I)$ является монотонно возрастающей функцией. Ее интенсивный рост при значениях тока 20-50 А сменяется более пологим и практически линейным увеличением в диапазоне 50-150 А. Ранее аналогичные зависимости с двумя характерными участками кривых $Q_{h}(I)$ наблюдались на катодах различной геометрии в диапазонах токов 50-200 и 200-600 A [6], в среде $\mathrm{Ar}[3]$, в среде $\mathrm{Ar}, \mathrm{He}, \mathrm{N}_{2}$ [4].

Функция $V_{h}(I)$ при увеличении тока от 20 до $150 \mathrm{~A}$ монотонно убывает от значения 2.7 до $1.1 \mathrm{~V}$. Характер зависимостей $Q_{h}(I)$ и $V_{h}(I)$ меняется в области 50-60 А, что свидетельствует об изменении теплового состояния катода. В эксперименте на токовых нагрузках ниже 50 А дуга приобретает контрагированную форму, что особенно заметно при $I=20$ А. При дальнейшем уменьшении тока привязка разряда к электроду становится неустойчивой и происходит срыв дуги.

Смена теплофизического режима заметно отражается на эрозии катода. В области 50-60 А токовая зависимость удельной эрозии $G(I)$ имеет минимальное значение, что подтверждает ее тепловую природу (испарительный механизм). Аналогичный характер функции $G(I)$ в диапазоне 100-700 А был зафиксирован на стержневом W-катоде в аргоновой дуге [4]. Зависимости, подобные левой ветви кривой $G(I)$, 


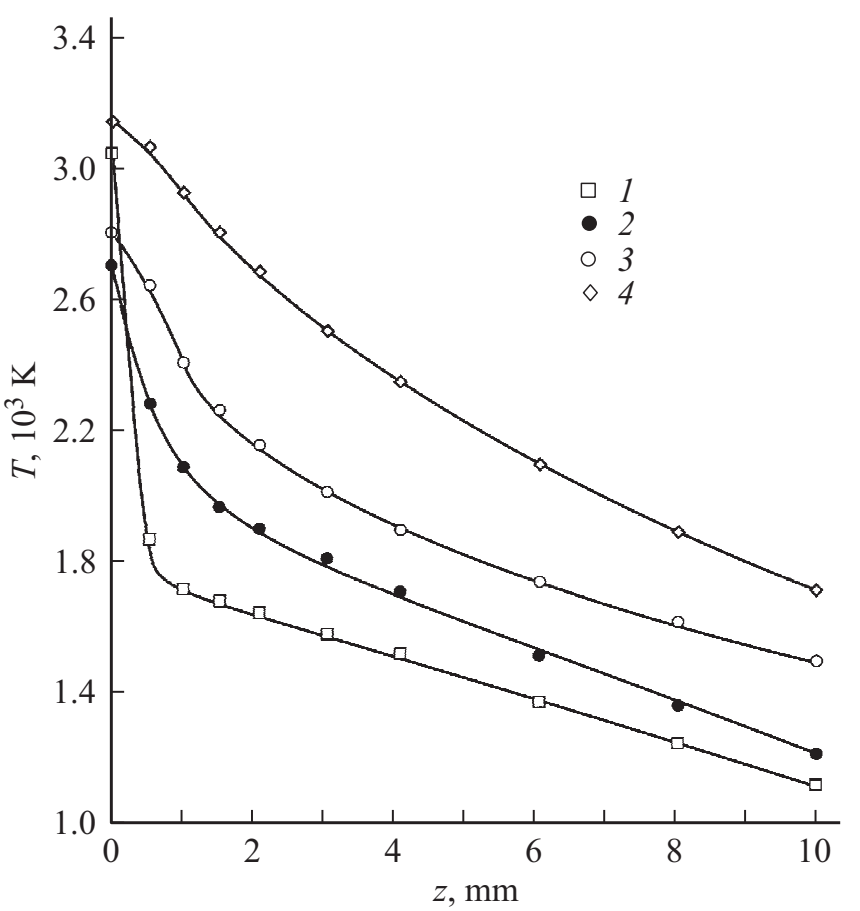

Рис. 2. Распределение температурного поля $T(z)$ по длине катода в зависимости от тока $\left(p=1.33 \cdot 10^{4} \mathrm{~Pa}\right) . \mathrm{I}, \mathrm{A}: 1-20,2-50,3-100,4-150$.

получены при измерении удельной эрозии активированных $\mathrm{W}$-катодов на токах 30-200 A [11].

Распределения температуры по длине катода $T(z)$ в зависимости от тока представлены на рис. 2. Интервалы $0-2$ и $2-10 \mathrm{~mm}$ соответствуют аксиальной проекции полусферического рабочего торца и цилиндрической части длины вылета электрода из держателя. При малых значениях тока $(I<50$ А) вблизи опорного пятна дуги наблюдаются большие градиенты температуры $d T / d z$. Например, при $I=20 \mathrm{~A}$ (рис. 2, кривая 1) на расстоянии всего $1 \mathrm{~mm}$ от горячего торца катода температура падает примерно на $1300 \mathrm{~K}$, кривая $T(z)$ претерпевает резкий излом. Далее на отрезке $10 \mathrm{~mm}$ температура катода практически линейно уменьшается на $700 \mathrm{~K}$.

3* Письма в ЖТФ, 2018, том 44, вып. 19 
С ростом тока средняя температура боковой поверхности катода заметно увеличивается, градиент $d T / d z$ около зоны контакта с дугой уменьшается и распределение $T(z)$ становится более пологим. Температура в зоне привязки дуги $T_{c}$ сначала уменьшается от $3060 \mathrm{~K}(20 \mathrm{~A})$ до $2670 \mathrm{~K}(50 \mathrm{~A})$, затем постепенно растет и достигает максимального значения $3120 \mathrm{~K}$ при $I=150 \mathrm{~A}$. Такое изменение функции $T_{c}(I)$ связано с контракцией приэлектродной области дуги на малых токах. Как известно [6], при контрагированной форме разряда повышаются температура прикатодной плазмы $T_{p}$ и плотность тока в пятне $j_{c}$. При $I=50$ А привязка разряда становится диффузной и охватывет всю площадь рабочего торца, что приводит к снижению $T_{c}$ и $j_{c}$. При увеличении токовой нагрузки до $150 \mathrm{~A}$ размер катодной привязки дуги остается постоянным. Это ведет к росту плотности тока в пятне $j_{c}$ и в объеме электрода $j(r, z)$. Соответственно повышается джоулев нагрев катода, происходит общий подъем профиля температуры $T(z)$.

Изучение распределения работы выхода электронов по длине катода выявило нелинейную зависимость $е \varphi(z)$ от тока (рис. 3). Исходное распределение $е \varphi(z)$ до зажигания дуги было равномерным и равным $2.92 \mathrm{eV}$. На рис. 3 привлекает внимание низкий интегральный уровень $e \varphi(z)$ при силе тока $50 \mathrm{~A}$, что хорошо коррелирует с минимальным значением $G(I)$ (рис. 1) и минимумом удельной эрозии $G(p)$ при $50 \mathrm{~A}[12]$. В активной зоне катодов $(z \approx 3 \mathrm{~mm})$ вне катодной привязки дуги с увеличением токовой нагрузки $е \varphi(z)$ растет, что связано с повышением температурного поля $T(z)$, интенсивным испарением и соответствующим обеднением присадкой матрицы W. Данный процесс характерен для зоны, непосредственно прилегающей к катодному пятну $(z \approx 2 \mathrm{~mm})$, и наиболее заметен при токе $20 \mathrm{~A}$ (кривая 1$)$. Здесь прирост работы выхода электронов $\Delta e \varphi$ наибольший $(0.65 \mathrm{eV})$. В центре катодного пятна с максимумом температуры (рис. 2) прирост $\Delta e \varphi$ составляет $0.32 \mathrm{eV}$. Этот экспериментальный результат можно объяснить явлением ионно-атомного рециклинга частиц металла в прикатодной области стационарного дугового разряда [13]. Вероятность ионизации испарившихся атомов металла больше вероятности ионизации молекул рабочего газа, поэтому атомы металла, достигая приэлектродной области, легко ионизируются электронами. Под влиянием электрического поля ионы переносятся обратно на поверхность катода, где восстанавливаются до атомов. Поэтому скорость испарения атомов присадки в области пятна и работа выхода электронов еф получаются ниже, чем за ее границами [8]. 


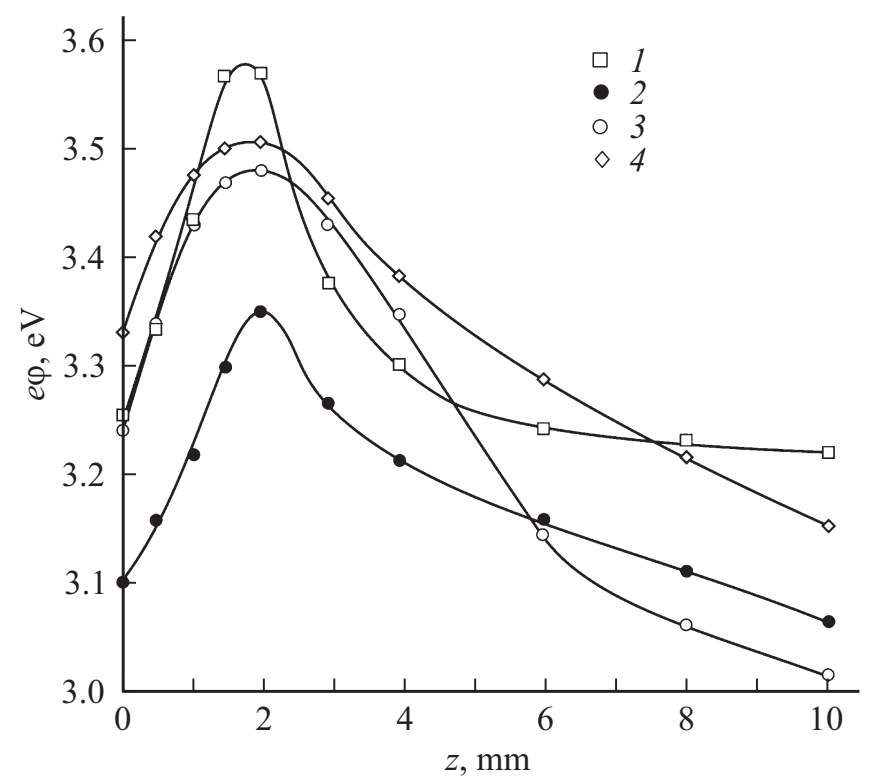

Рис. 3. Распределение работы выхода электронов $е \varphi(z)$ по длине катода в зависимости от тока $\left(p=1.33 \cdot 10^{4} \mathrm{~Pa}\right)$. Обозначение кривых то же, что на рис. 2.

В [14] показано, что в аргоновой дуге атмосферного давления расчетная глубина ионизационного слоя тория составляет $4 \mu \mathrm{m}$, вольфрама $-9 \mu \mathrm{m}$. Экспериментальное изучение процессов, протекающих в этих слоях, представляет собой крайне сложную задачу. Впервые параметры процессов определены спектральным методом в аргоновой дуге пониженного давления [13]. В работе [7] методом электронной оже-спектроскопии в катодных пятнах активированных вольфрамовых электродов обнаружены тонкие слои атомов присадки (La, Y, Th), постепенно выгорающих в течение $60-80 \mathrm{~min}$ работы плазмотронов. Детальное изучение морфологии и атомного состава рабочего торца катодов $\left(\mathrm{W}+2 \% \mathrm{ThO}_{2}\right)$ выявили три характерные зоны локализации атомов Th (зоны высокой эрозии, истощения и обогащения торием) [15]. Размеры этих зон и количественное содержание Тh в них определяются как поверхностными явлениями взаимодействия плазмы с металлом,

Письма в ЖТФ, 2018, том 44, вып. 19 
так и процессами диффузии присадки и рекристаллизации матрицы. Об этом свидетельствует ход кривых $е \varphi(z)$ на рис. 3. Например, в катодном пятне на расстоянии $1 \mathrm{~mm}$ от центра торца при токах 20 , $100,150 \mathrm{~A}$ значения е $\varphi$ примерно равны $3.45 \mathrm{eV}$, при этом температуры отличаются более чем на $10^{3} \mathrm{~K}$ (рис. 2). Следовательно, в формировании атомного слоя Тh на поверхности катода кроме ионно-атомного рециклинга существенную роль играют процессы тепломассопереноса в теле электрода. Самый низкий уровень еф при $I=50$ А (рис. 3) свидетельствует о реализации оптимального теплового состояния, когда унос присадки в процессе испарения компенсируется ее диффузионным притоком из глубины к рабочей поверхности электрода. Вне активной зоны катода при $z>3 \mathrm{~mm}$ (рис. 3) корреляция между профилем $е \varphi(z)$ и уровнем температурного поля $T(z)$ нарушается. Очевидно, в данной области $е \varphi(z)$ в значительной степени определяется процессами внутри катода, такими как диффузия и подвижность атомов, рекристаллизация материала и т.д. Количественный анализ возможен при численном моделировании процессов тепломассопереноса на основе их эволюционной физико-математической модели $[16,17]$.

Таким образом, в работе изучены закономерности интегральных параметров активированных термоэмиссионных катодов в зависимости от токовой нагрузки в дуговом разряде пониженного давления $p=1.33 \cdot 10^{4} \mathrm{~Pa}$. Выявлено оптимальное значение тока с минимумом удельной эрозии, ранее наблюдаемым только в разрядах атмосферного давления. Впервые измерены профили температурного поля $T(z)$ и работы выхода электронов $е \varphi(z)$ по длине электродов при различных значениях силы тока. Полученные результаты подтверждают явление ионно-атомного рециклинга частиц металлов в приэлектродной зоне стационарного дугового разряда.

\section{Список литературы}

[1] Fauchais P., Vardelle A. // IEEE Trans. Plasma Sci. 1997. V. 25. N 6. P. $1258-1280$.

[2] Будин А.В., Пинчук М.Э., Кузнецов В.Е., Рутберг Ф.Г. // Письма в ЖТФ. 2014. T. 40. B. 23. C. 49-57.

[3] Гордеев В.Ф., Пустогаров А.В. Термоэмиссионные дуговые катоды. М.: Энергоатомиздат, 1988. $192 \mathrm{c.}$

Письма в ЖТФ, 2018, том 44, вып. 19 
[4] Жуков М.Ф., Засыпкин И.М., Тимошевский А.Н., Михайлов Б.И., Десятков Г.А. Электродуговые генераторы термической плазмы. Новосибирск: Наука, 1999. 712 c.

[5] Nemchinsky V. // IEEE Trans. Plasma Sci. 2014. V. 42. N 1. P. 199-215.

[6] Жуков М.Ф., Козлов Н.П., Пустогаров Л.В., Аныпаков А.С., Хвесюк В.И., Дюжев Г.А., Дандарон Г.-Н.Б. Приэлектродные процессы в дуговых разрядах. Новосибирск: Наука, 1982. 157 с.

[7] Zhou X., Heberlein J. // J. Phys. D: Appl. Phys. 1998. V. 31. P. 2577-2590.

[8] Цыдыпов Б.Д. // Письма в ЖТФ. 2010. Т. 36. В. 14. С. 88-94.

[9] Цыдыпов Б.Д. // Письма в ЖТФ. 2015. Т. 41. В. 20. С. 66-73.

[10] Савищкий Е.М., Буров И.В., Корольков В.А., Иванюшенко Е.В., Литвак Л.Н., Кузнещов В.А. // Физика и химия обраб. материалов. 1985. № 2. C. $121-123$.

[11] Casado E., Colomer V., Muñoz-Serrano E., Sicilia R. // J. Phys. D: Appl. Phys. 2002. V. 35. P. $992-997$.

[12] Цыдыпов Б.Д. // ЖТФ. 2007. Т. 77. В. 4. С. 135-137.

[13] Жуков М.Ф., Козлов Н.П., Гужкков В.В., Хвесюк В.И., Цыдыпов Б.Д. // ДАН CCCP. 1981. T. 260. № 6. C. 1354-1356.

[14] Ortega D., Sullero Marin J.A., Muñoz-Serrano E., Casado E. // J. Phys. D: Appl. Phys. 2009. V. 42. P. 085202 (1-8).

[15] Sullero J.A., Ortega D., Muñoz-Serrano E., Casado E. // J. Phys. D: Appl. Phys. 2010. V. 43. P. 185204 (1-8).

[16] Цыдыпов Б.Д., Симаков И.Г. // ЖТФ. 2010. Т. 80. В. 11. С. 115-121.

[17] Цыдыпов Б.Д. // ТВТ. 2014. Т. 52. № 4. С. 609-612.

Письма в ЖТФ, 2018, том 44, вып. 19 